\title{
Inequalities in disability-free life expectancy by social class and area type: England, 2001-03
}

Chris White and Grace Edgar Office for National Statistics

\section{Abstract}

\section{Background}

Disability-free life expectancy (DFLE) is an important indicator which combines longevity with functional health status. This article examines inequalities in DFLE by socio-economic position in England, and between Local Authorities (LAs) in the deprived 'Spearhead group' and other LAs.

\section{Methods}

Census and vital event data available from the ONS Longitudinal Study were used to calculate estimates of DFLE based on limiting long-term illness or disability status for each Registrar General's Social Class (RGSC) in 2001-03, in England as a whole and within the 'Spearhead group' and non-Spearhead LAs.

\section{Results}

A predominantly linear relationship was present with DFLE increasing with rising social class. The differences observed in DFLE at birth and at age 65 between people assigned to the professional and unskilled manual social classes were statistically significant and substantial, demonstrating a clear social inequality in the amount of life, the functional health status during those years lived, their absolute number, and thus the relative proportion of life spent free from a limiting long-term illness or disability.

Among professional men, no statistically significant differences in DFLE at birth were found between the 'Spearhead group' and the non-Spearhead LAs. However, men assigned to the other social classes in the 'Spearhead group' were disadvantaged in terms of lower DFLE than their counterparts in the non-Spearhead LAs. Manual women living in non-spearhead LAs had comparable DFLE to women assigned to the managerial and technical and skilled non-manual social classes living in the 'Spearhead group'.

The magnitude of inequality in DFLE at birth between professionals and the unskilled manual class in the proportion of life spent free of a limiting long-term illness or disability also varied between the 'Spearhead group' and non-Spearhead LAs: among men, a difference of 7.7 per cent was present in non-Spearhead LAs, compared with 13.1 per cent 
in the 'Spearhead group'; among women, the equivalent differences were 5.2 per cent and 9.4 per cent.

\section{Conclusions}

These results confirm that the assumptions made with regard to sex differences in DFLE need to be set in the context of socio-economic position, and assumptions made regarding sex and social differences need to set in the context of geography. The scale of the inequalities shown is important for policy responses and understanding of differences in service needs.

\section{Contents}

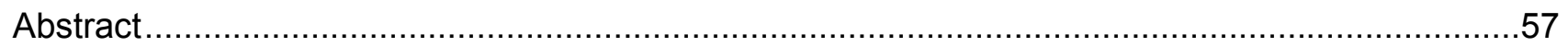

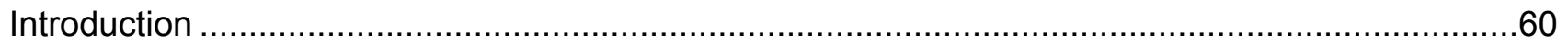

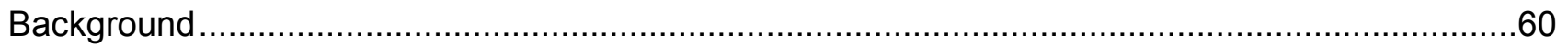

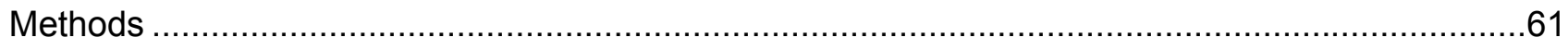

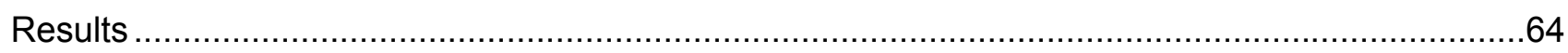

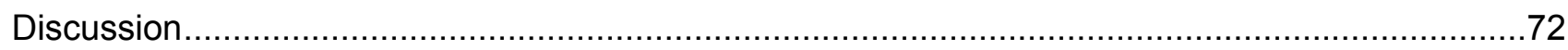

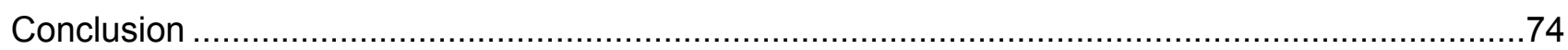

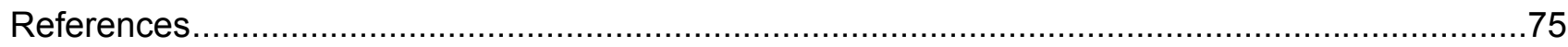

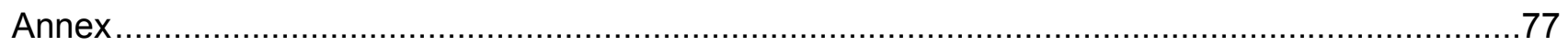




\section{List of Tables}

Table 1 Gradient in LE and DFLE between professionals and the unskilled: men and women in England, 2001-03...

Table 2 Summary of differences in DFLE between professionals and the unskilled at birth and at age 65: 2001-03, England

Table 3 Inequality in DFLE at birth and at age 65 by 'Spearhead' classification: men and women in English LAs, 2001-03

Table 4 Differences in DFLE at birth and at age 65 by RGSC between 'Spearhead' and nonSpearhead areas: men and women in English LAs, 2001-03 ..............................70

Table A1 Life Expectancy and DFLE at birth and at age 65 by RGSC: England, 2001-03 ....77

Table A2 Life Expectancy and DFLE at birth and at age 65, by RGSC in the 'Spearhead group' and non-Spearhead LAs: men and women in English LAs, 2001-03. .79

\section{List of Figures}

Figure 1 DFLE at birth in years with $95 \%$ confidence intervals by sex and RGSC: England, 2001-03.....

Figure 2 DFLE at age 65 in years with 95\% confidence intervals by sex and RGSC: England, 2001-03

Figure 3 DFLE at birth in years by RGSC \& Spearhead Area status: men in England, 200103

Figure 4 DFLE at birth in years by RGSC \& Spearhead Area status: women in England, 2001-03.....

Figure $5 \quad$ Per cent of life expectancy at birth spent free of LLTID by RGSC and 'Spearhead' classification: men and women in English LAs, 2001-03

Figure 6 Per cent of life expectancy at age 65 spent free of LLTID by RGSC and 'Spearhead' classification: men and women in English LAs, 2001-03 


\section{Introduction}

Measuring the combined impact of mortality and functional health status provides greater insight into social differences in health than measures relying solely on longevity. This article provides analyses of Disability-Free Life Expectancy (DFLE) by the Registrar General's Social Class (RGSC) in England, and also compares the social patterns observed in those local authorities (LAs) which are in the Department of Health's 'Spearhead group' with other LAs. The 'Spearhead group' are those identified as the most socio-economically deprived LAs in England.

This analysis was funded by the Department of Health, as part of a wider programme of work focusing on the measurement of inequalities in health.

A companion article, in the same edition of Health Statistics Quarterly, presents a similar analysis for healthy life expectancy (HLE).

\section{Background}

Since the 1990s, analyses of DFLE have been widely reported; ecological studies have investigated the influence of area deprivation and DFLE, both in Great Britain ${ }^{1,2,3}$ and abroad. ${ }^{4,5}$ British results show that males and females living in the least deprived twentieth of electoral wards in 2001 live an additional 14.1 years disability-free than those living in the most deprived twentieth. ${ }^{3}$ Analyses by administrative geography using the decennial census of population in 2001 observed a marked gap in DFLE between local authority areas: those areas with higher life expectancy (LE) also experienced higher DFLE, suggesting individuals in areas with high LE are advantaged both in longevity overall and longevity without disability. ${ }^{6}$

Previous analyses of occupation-based social differences in health expectancy in Great Britain found that men in professional occupations lived nine more years free of disability than men working in unskilled manual occupations, ${ }^{7}$ representing a more substantial inequality than the difference in life expectancy. ${ }^{8,9,10}$ Consequently, the magnitude of social inequality in functional health status is somewhat hidden in comparisons restricted to longevity alone. The Medical Research Council funded Cognitive Function and Ageing Study found the prevalence of disability among men occupying RGSC social classes I and II to be lower at ages 65-69 than those occupying social classes III-V; while professionals and managers can expect to live a further 14 years disability-free, those occupying the other social classes only experienced a further 11.5 years on average. For women the disparity was smaller but still present. ${ }^{11}$

The Department of Health's 'Spearhead group' of LAs consists of those identified as the most socio-economically deprived in England. The criteria were reported in the Government's Spending Review of 2004. The 'Spearhead group' 12 consists of those LAs placed in the bottom fifth nationally in three or more of the following five indicators:

- Male LE at birth

- Female LE at birth

- Cancer mortality rate in the under $75 \mathrm{~s}$

- Cardiovascular disease mortality rate in the under $75 \mathrm{~s}$

- Index of Multiple Deprivation 2004 (local authority summary) average score 
For a list of LAs included in the 'Spearhead group', see Table A1 in the Annex of the companion article on healthy life expectancy in the same issue of Health Statistics Quarterly.

The objectives of this article are to report the pattern in DFLE by socio-economic position and scale of inequality in England, and to determine the consistency of this pattern and its scale between the 'Spearhead group' and non-Spearhead LAs.

\section{Methods}

\section{Data source and study population}

The results presented are based on the data available in the ONS Longitudinal Study (LS). ${ }^{13,14}$ The LS is a 1 per cent representative sample of the population of England and Wales, containing linked census and life events records since 1971, including births, deaths and embarkations. The linking of census records enables researchers to take account of historical census characteristics of those LS members with census histories. In this research, use of linked individual data and household level data has facilitated the attribution of social class based on occupation and employment status for those without occupational details recorded at 2001, allowing these study members to be included in the analysis.

The selection criteria which were applied to select the study population for this analysis are shown in Box 1. The study population was followed for mortality and embarkation events occurring in the period 29 April 2001 until the end of December 2003; those LS members who left the country during the follow-up period contributed person years of risk up to the point of embarkation. Functional health status was determined using responses to the limiting long-term illness or disability (LLTID) question included on the 2001 Census form and was assumed to remain constant throughout the entirety of the follow-up period.

\section{Box $1 \quad$ Selection criteria}

\section{All members of the ONS Longitudinal Study who:}

- were enumerated at the Census of population in 2001 as resident in England

- could be assigned a valid RGSC class from their own census records or those of family members

- were traced at the National Health Service Central Register, ensuring the correct linkage of census and death records

- had a 2001 Census record containing a completed limiting long-term illness or disability question with which to determine disability status

A total of 510,365 LS members resident in England were enumerated at the 2001 Census: of these, 472,560 were traced at the National Health Service Central Register, could be allocated a social class, and had limiting long-term illness or disability (LLTID) data available. Among the study 
population, a total of 12,091 deaths and 881 embarkations were recorded, and they contributed a total of $1,238,031$ person years of risk.

In this analysis the person years of risk contributed, rather than the number of people included, were used to calculate all mortality and prevalence rates of LLTID in order to reflect the duration of time in the given health state assumed, and take account of the ageing of the study population during follow-up.

\section{The allocation of social class}

Linked census records from 1971 onwards and the records of family members residing in the LS member's household were used to assign an RGSC class, based on an algorithm of assignment used previously in analyses of LE by social class. ${ }^{9}$ The six RGSC classes used in this analysis, with examples of the occupations included in each class, are shown in Box 2.

\section{Box 2 Registrar General's Social Class based on occupation}

\begin{tabular}{ll}
\hline Class description & Examples of occupations: \\
\hline Non-manual & \\
I Professional & Doctors, chartered accountants, professionally qualified engineers \\
II Managerial \& technical/intermediate & Managers, journalists, school teachers \\
IIIN Skilled non-manual & Clerks, cashiers, retail staff \\
Manual & $\begin{array}{l}\text { Supervisors of manual workers, plumbers, electricians, goods vehicle } \\
\text { drivers } \\
\text { IIIM Skilled manual }\end{array}$ \\
IV Partly skilled & $\begin{array}{l}\text { Warehousemen, security guards, machine tool operators, } \\
\text { cabourers, cleaners and messengers }\end{array}$ \\
V Unskilled & Labourers \\
\hline
\end{tabular}

In allocating an RGSC social class, priority was given to the study member's own first reporting of occupation and employment status at a census. If an LS member's own social class was not available, social class was allocated on the basis of other household members in the following order: firstly, the member's spouse; secondly, the member's parents (father's or failing that mother's). For those study members aged less than 16 years in 2001, social class was assigned on the basis of parental social class reported in 2001 (father's or failing that mother's). This follows the approach to social class allocation used in analyses of LE by social class reported by ONS using the LS. ${ }^{8,9,10}$

\section{Calculation of disability-free life expectancy}

The standard method, based on the Sullivan Life Table ${ }^{15}$ (the 'Sullivan method') was used to calculate DFLE at birth and at age 65 for each social class for England as a whole and for those living in the 'Spearhead group' and non-Spearhead LAs in 2001. The steps in this calculation are recorded in Box 3 below. 


\section{Box 3 The Sullivan method for calculating DFLE}

1 For each age/sex group obtain the life table schedules $I_{x}$ and the expectation of life $e_{x}$ for the period of interest. Calculate ${ }_{n} L_{x}=e_{x} I_{x}-e_{x+n} I_{x+n}$ where ${ }_{n} L_{x}$ is the conventional life table measure of the average number of years lived in the age interval $\mathbf{x}$ to $\mathbf{x}+\mathbf{n}$

2 Obtain the LLTID rate ${ }_{n} \mathbf{d}_{\mathbf{x}}$ in each age group observed in a study population. Calculate the average number of persons aged $\mathbf{x}$ to $\mathbf{x}+\mathbf{n}$ living free of LLTID in each age/sex group as ${ }_{n} \operatorname{LWD}_{x}={ }_{n} L_{x}\left(1-{ }_{n} d_{x}\right)$

3 Calculate life expectancy without LLTID as $\operatorname{DFLE}_{\mathbf{x}}=\left(\Sigma_{\mathbf{n}} \mathbf{L} \mathbf{W D}_{\mathbf{x}}\right) / \mathrm{I}_{\mathbf{x}}$ and the summation is from age $\mathrm{x}$ upwards

4 Calculate the variation in the precision due to the variance in the probability of the prevalence part of DFLE and due to the variance in the mortality part of DFLE

The variance in the mortality part of DFLE is given as

$$
\sum_{x=0}^{W-1}\left\{I_{x}{ }^{2}\left[\left(1-a_{x}\right) n\left(1-\pi_{x}\right)+D F L E_{x+n}\right]^{2} S^{2}\left(p_{x}\right)\right\} / I_{x}^{2}
$$

while the variance of the prevalence part is given as:

$$
\mathrm{S}^{2}\left(\mathrm{DFLE}_{\mathrm{x}}\right) \approx \frac{1}{\mathrm{I}_{\mathrm{x}}{ }^{2}} \sum_{\mathrm{X}=0}^{W} \mathrm{~L}_{\mathrm{x}}{ }^{2} \frac{\pi_{\mathrm{x}}\left(1-\pi_{\mathrm{x}}\right)}{\mathbf{N}_{\mathrm{x}}}
$$

where $\mathbf{N}_{\mathbf{x}}$ is the number of persons in the age interval taking part in the study

$\mathrm{I}_{\mathbf{x}}$ is the probability of survival to age $\mathbf{x}$

$L_{\mathbf{x}}$ is person years lived in the age interval free of LLTID

$\pi_{\mathbf{x}}$ is the proportion of people in age interval with LLTID

Therefore, the total variance from which the standard errors and Cls are calculated is given as:

$$
\sum_{x=0}^{W-1}\left\{I_{x}{ }^{2}\left[\left(1-a_{x}\right) n\left(1-\pi_{x}\right)+D L_{x+n}\right]^{2} S^{2}\left(p_{x}\right)\right\} / I_{x}{ }^{2}+S^{2}\left(D F L E_{x}\right)
$$

The DFLE measure is based on self-reported LLTID, making use of the 2001 Census question, as shown in Box 4.

The measure was computed at birth and at age 65 for each sex and social class in each area type (i.e. 'Spearhead group' and non-Spearhead LAs). The DFLE estimates are calculated by combining age and sex specific mortality rates (life tables), with age and sex specific rates of LLTID. DFLE at birth is defined as the average number of years a new-born baby would live free of a LLTID if he or she experienced the particular social class's age-specific mortality and LLTID prevalence rates (as measured in 2001) throughout his or her life beyond birth. 
This measure reflects the current mortality and LLTID experience among those assigned an RGSC social class: they do not indicate how long people in a specific social class can expect to live in future free of a LLTID. This is because mortality and LLTID rates are likely to change in the future; a person's socio-economic position may also change during their life.

\section{Box 4}

\section{Census Limiting long-term illness or disability question}

Do you have any long-term illness, health problem or disability which limits your daily activities or the work you can do? Include problems which are due to old age

- Yes

- No

\section{Those responding 'Yes' were classified as having a limiting long-term illness or} disability

The extent of self-reporting of LLTID by household members across the age spectrum is uncertain. While those of working age are likely to have completed the individual census form themselves, it is likely that a significant proportion of those aged 15 years or younger will have had this question completed on their behalf by an adult household member.

\section{Results}

The results are described in two sections: firstly, DFLEs are reported for England by the RGSC expanded class breakdowns; secondly, class specific DFLEs in English 'Spearhead group' LAs were compared with DFLE in non-Spearhead English LAs. For a socio-demographic overview, please see the companion article on healthy life expectancy in the same issue of Health Statistics Quarterly.

\section{Disability-free life expectancy by social class}

A statistical overview of DFLE at birth and at age 65 by RGSC is tabulated in Table A1 in the Annex, and pictorially represented in Figures 1 and 2 below.

Male DFLE at birth and at age 65 showed a pronounced social inequality (Figures 1 and 2), clearly exceeding the gradient in LE (Table 1). Professional men at birth could expect to live 13.4 years longer free of a LLTID than men assigned to the unskilled social class; the latter class were observed to survive without a LLTID to age 57 on average. At age 65, a gap of 5.3 years was present between these two classes. Professional men had statistically significantly higher DFLE than all other classes, while men in the unskilled manual social class had statistically significantly lower DFLE both at birth and at age 65 . 
Figure 1 DFLE at birth in years with $95 \%$ confidence intervals by sex and RGSC: England, 2001-03

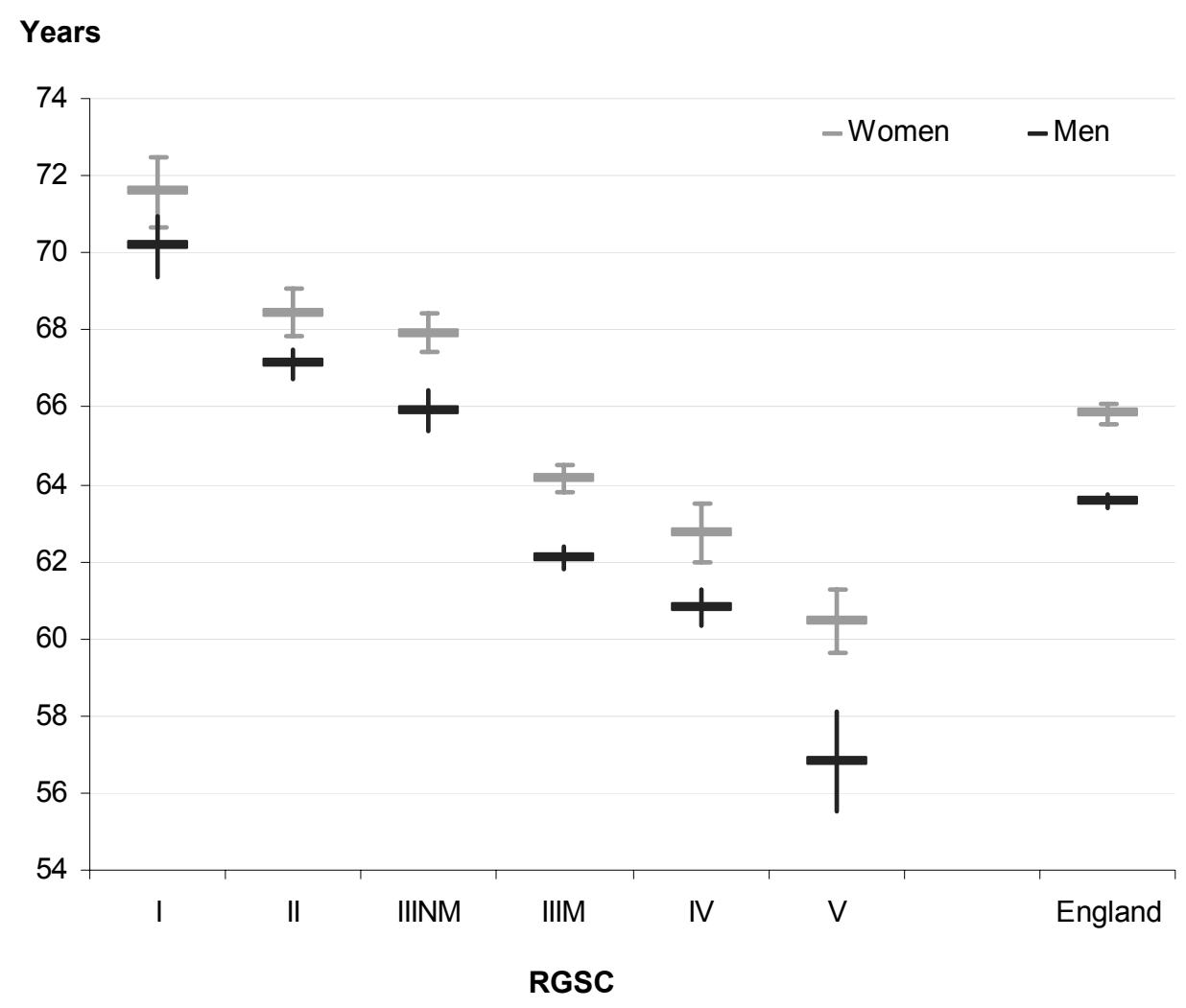

Figure 2 DFLE at age 65 in years with $95 \%$ confidence intervals by sex and RGSC: England, 2001-03

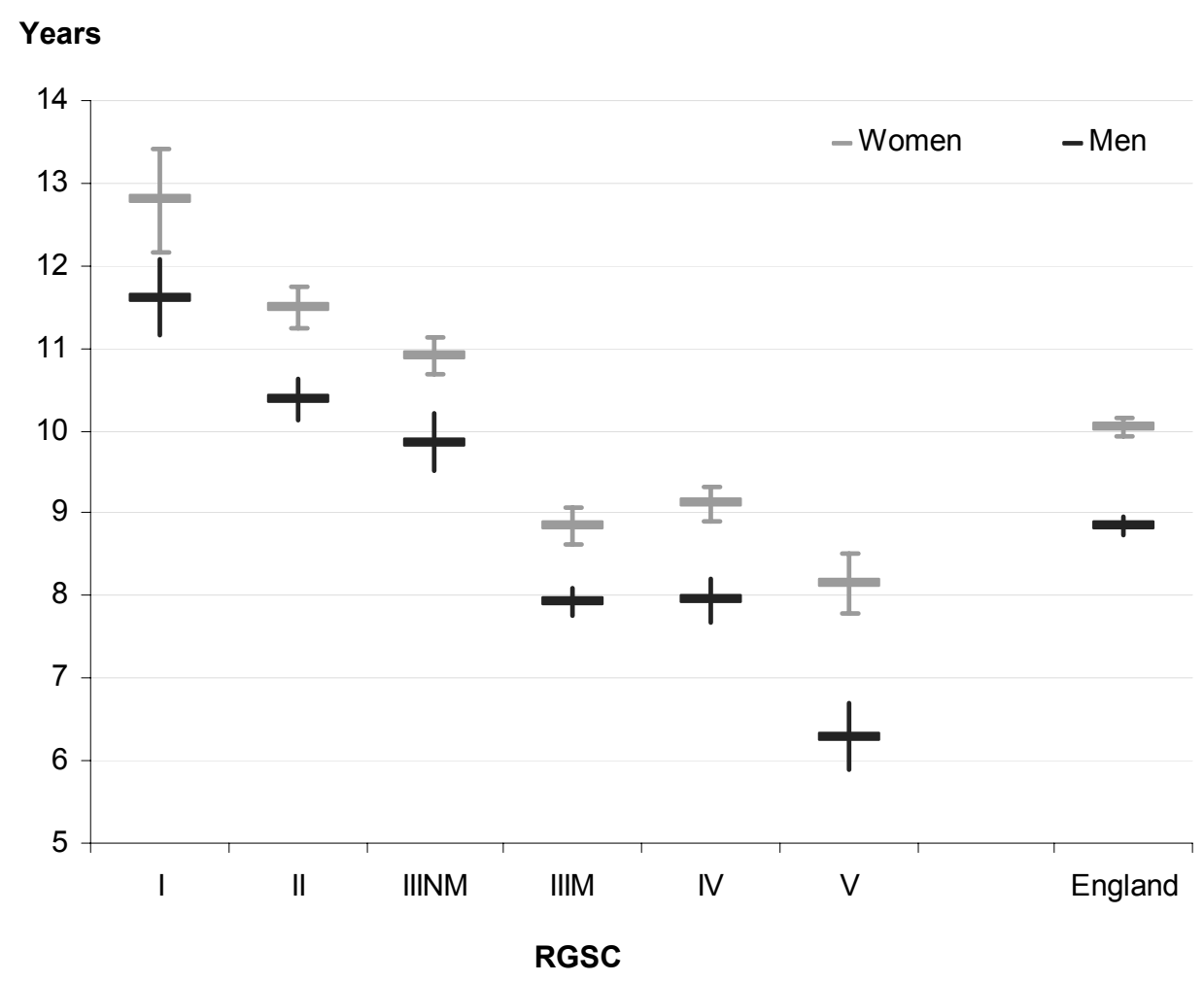


For women, the inequality in DFLE also exceeded the inequality in LE: professional women at birth could expect to live an additional 11.2 years free of LLTID compared with unskilled women. At age 65 , the gap in DFLE between these classes was 4.7 years. While women experienced a higher DFLE within classes than men, men assigned to the non-manual social classes had a higher DFLE than women assigned to the manual social classes.

The gradients in DFLE between professionals and the unskilled are greater than those of LE both at birth and at age 65 (Table 1): at birth, approximately twice the magnitude; at age 65, the gradients are larger, but the difference between gradients in LE and DFLE are more prominent among men than among women.

Table 1 Gradient in LE and DFLE between professionals and the unskilled: men and women in England, 2001-03

\begin{tabular}{|l|r|r|r|r|}
\hline Sex & LE at birth & DFLE at birth & LE at age 65 & DFLE at age 65 \\
\hline Men & 1.09 & 1.23 & 1.31 & 1.85 \\
\hline Women & 1.09 & 1.18 & 1.29 & 1.57 \\
\hline
\end{tabular}

A summary of the differences in DFLE between the extremes of the social class scale are reported in Table 2 below.

\section{Table $2 \quad$ Summary of differences in DFLE between professionals and the unskilled at birth and at age 65: 2001-03, England}

\begin{tabular}{|c|c|c|c|}
\hline & & \multicolumn{2}{|c|}{ Disability-free Life Expectancy } \\
\hline Difference at birth & Sex & Years of life spent free of disability & $\begin{array}{r}\text { Proportion of life spent free of } \\
\text { disability }\end{array}$ \\
\hline \multirow{2}{*}{ I Professional - V Unskilled } & Men & 13.4 & $10.2 \%$ \\
\hline & Women & 11.1 & $6.9 \%$ \\
\hline Difference at age 65 & Sex & Years of life spent free of disability & $\begin{array}{r}\text { Proportion of life spent free of } \\
\text { disability }\end{array}$ \\
\hline \multirow{2}{*}{ I Professional - V Unskilled } & Men & 5.3 & $18.3 \%$ \\
\hline & Women & 4.7 & $10.2 \%$ \\
\hline
\end{tabular}




\section{Disability-free life expectancy by social class and LA 'Spearhead' status}

The estimates of DFLE at birth and at age 65 for RGSC classes in the 'Spearhead group' and nonSpearhead LAs are reported in Table A1 in the Annex and illustrated in Figures 3 and 4 at birth. The social pattern of DFLE in both the 'Spearhead group' and Non-Spearhead LAs is largely consistent with the national pattern for England. However, the within class level of DFLE is lower in the 'Spearhead group'.

Among professional men, no statistically significant differences in DFLE at birth were found between the 'Spearhead group' and the non-Spearhead LAs. However, men assigned to the other social classes in the 'Spearhead group' were disadvantaged in terms of lower DFLE than their counterparts in the non-Spearhead LAs (Figure 3). Among the intervening social classes, a notably higher DFLE was observed among men assigned to the skilled manual social class in the nonSpearhead LAs compared with skilled non-manual men in the 'Spearhead group', and the former also had a comparable DFLE with men assigned to the managerial and technical social class in the 'Spearhead group' (Figure 3). A similar social pattern is also present among women (Figure 4).

Figure 3 DFLE at birth in years by RGSC \& Spearhead Area status: men in England, 2001-03

\section{Years}

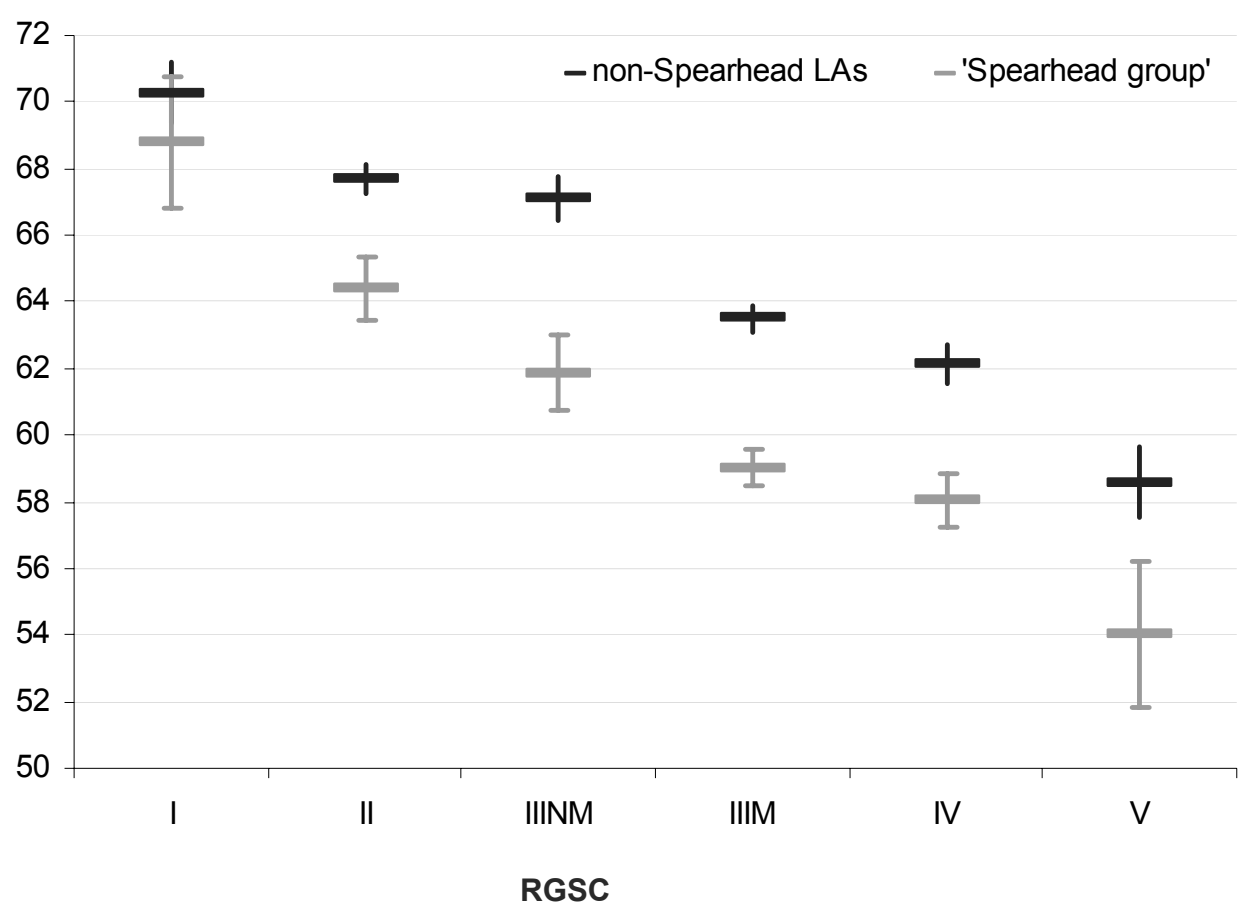




\section{Figure 4 DFLE at birth in years by RGSC \& Spearhead Area status:} women in England, 2001-03

\section{Years}

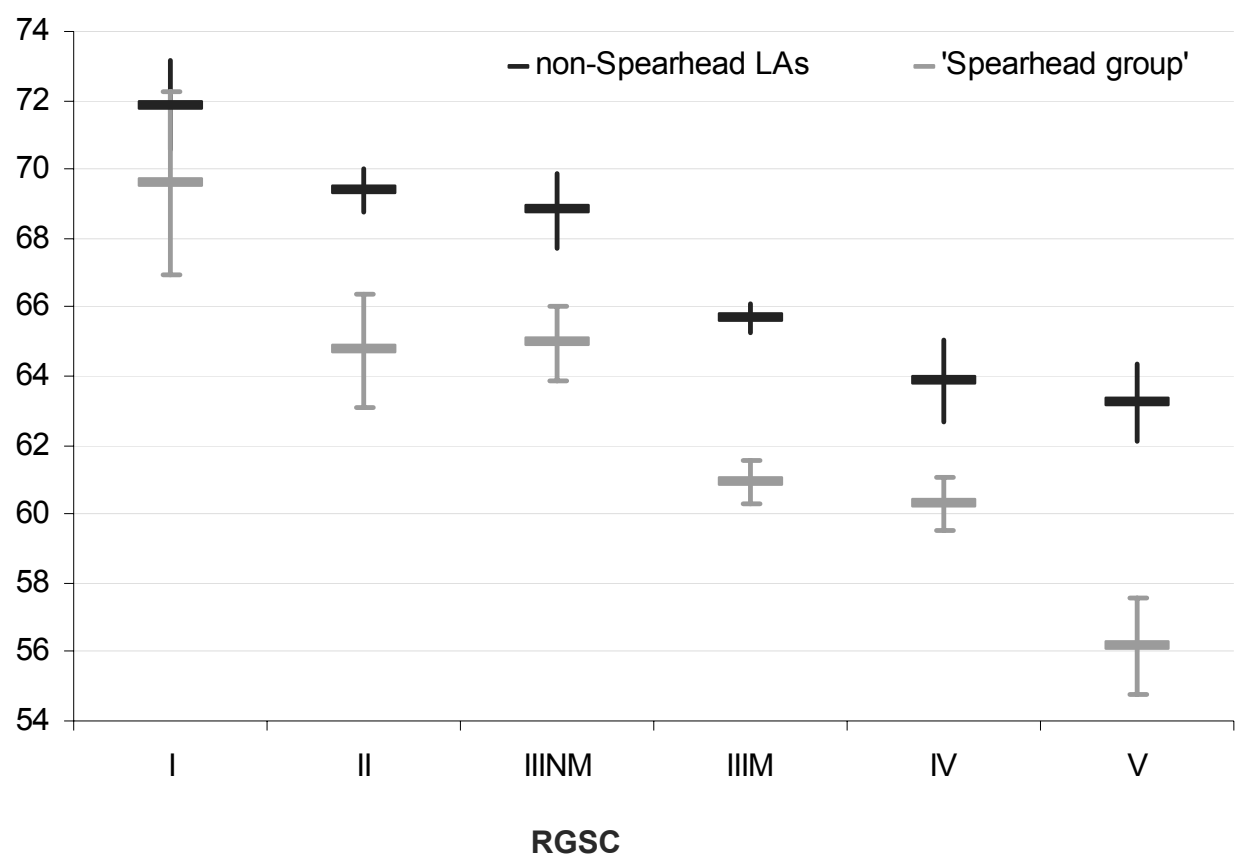

At age 65, men and women assigned to classes other than the professional class again had statistically significantly lower DFLE if resident in the 'Spearhead group' (Table A2 in the Annex ).

The highest DFLE at birth is found among professional women living in the non-Spearhead LAs, where expectation of life without a LLTID was 71.9 years. The lowest DFLE of 54.0 years was found in men assigned to the unskilled social class living in the 'Spearhead group', a gap of 17.9 years in total. In general, the effect of residence in the 'Spearhead group' was smaller than the effect of social class, but also adds to the magnitude of inequality in DFLE observed.

In the 'Spearhead group', the gap in DFLE at birth between professional men and unskilled men was greater than in the non-Spearhead LAs (Table 3): 11.7 years in the non-Spearhead LAs and 14.8 years in the 'Spearhead group'. A slightly larger differential is observed in the inequality gap between area types in women.

At age 65, no difference in the gap in social inequality between area types was present among men; but among women the gap is slightly larger in the 'Spearhead group'. Table 4 compares the differences in DFLE for individuals living in the 'Spearhead group' and the non-Spearhead LAs within each social class, separately for men and women at birth and at age 65 . 


\section{Table $3 \quad$ Inequality in DFLE at birth and at age 65 by 'Spearhead'} classification: men and women in English LAs, 2001-03

\begin{tabular}{lccrr}
\hline non-Spearhead LAs & MEN & \multicolumn{2}{c}{ WOMEN } \\
\hline RGSC & DFLE at birth & DFLE at age 65 & DFLE at birth & DFLE at age 65 \\
Professionals & 70.3 & 11.8 & 71.9 & 13.1 \\
Unskilled & 58.6 & 6.8 & 63.2 & 9.1 \\
Inequality gap & 11.7 & 5.0 & 8.7 & WOMEN \\
'Spearhead group' & MEN & & DFLE at birth & DFE at age 65 \\
RGSC & DFLE at birth & DFLE at age 65 & 69.6 & 11.1 \\
Professionals & 68.8 & 10.5 & 56.2 & 6.7 \\
Unskilled & 54.0 & 5.5 & 13.4 & 4.4 \\
Inequality gap & 14.8 & 5.0 & $\mathbf{4}$ & $\mathbf{0 . 4}$ \\
$\begin{array}{l}\text { Difference in gap between } \\
\text { areas }\end{array}$ & 3.1 & $\mathbf{0 . 0}$ & & \\
\hline
\end{tabular}

The second section of Table 4 reports the combined effect of social class and area type. For DFLE at birth in men and women there was a difference of 16 years between professionals living in the non-Spearhead LAs and the unskilled living in the 'Spearhead group'. The difference in the proportion of life spent free of a LLTID is 14 per cent for men and 10 per cent for women.

For DFLE at age 65 , there is a difference of 6-8 years. The comparable difference in the proportion of life spent free of a LLTID was approximately 24 per cent for men and 16 per cent for women.

\section{Relative differences in DFLE by social class and Spearhead status}

The relative inequality in DFLE between social classes and between area types is also substantial, demonstrating those in disadvantaged circumstances not only experience shorter expectations of life, but also shorter proportions of life expectancy free from a LLTID (Figure 5). 


\section{Table 4 Differences in DFLE at birth and at age 65 by RGSC between 'Spearhead' and non-Spearhead areas: men and women in English LAs, 2001-03}

\begin{tabular}{|c|c|c|c|c|}
\hline \multirow{2}{*}{$\begin{array}{l}\text { Non-spearhead - 'Spearhead' areas } \\
\text { RGSC }\end{array}$} & \multicolumn{2}{|c|}{$\begin{array}{c}\text { Disability-free life expectancy } \\
\text { at Birth }\end{array}$} & \multicolumn{2}{|c|}{$\begin{array}{l}\text { Disability-free life expectancy } \\
\text { at age } 65\end{array}$} \\
\hline & $\begin{array}{r}\text { Years of life } \\
\text { spent free of } \\
\text { LLTID }\end{array}$ & $\begin{array}{r}\text { Proportion of life } \\
\text { spent free of } \\
\text { LLTID }\end{array}$ & $\begin{array}{r}\text { Years of life } \\
\text { spent free of } \\
\text { LLTID }\end{array}$ & $\begin{array}{l}\text { Proportion of life } \\
\text { spent free of } \\
\text { LLTID }\end{array}$ \\
\hline I & 1.5 & $1.0 \%$ & 1.3 & $3.3 \%$ \\
\hline II & 3.3 & $3.3 \%$ & 1.2 & $7.2 \%$ \\
\hline IIINM & 5.3 & $3.0 \%$ & 1.9 & $6.6 \%$ \\
\hline IIIM & 4.5 & $4.7 \%$ & 2.0 & $10.6 \%$ \\
\hline IV & 4.1 & $4.6 \%$ & 1.3 & $7.7 \%$ \\
\hline V & 4.5 & $6.3 \%$ & 1.3 & $9.0 \%$ \\
\hline \multicolumn{5}{|l|}{ Women } \\
\hline I & 2.3 & $0.4 \%$ & 2.0 & $1.6 \%$ \\
\hline II & 4.6 & $2.7 \%$ & 1.9 & $7.7 \%$ \\
\hline IIINM & 3.9 & $4.0 \%$ & 1.8 & $7.5 \%$ \\
\hline IIIM & 4.8 & $4.1 \%$ & 1.5 & $5.8 \%$ \\
\hline IV & 3.5 & $5.1 \%$ & 1.6 & $7.9 \%$ \\
\hline V & 7.1 & $4.6 \%$ & 2.4 & $8.8 \%$ \\
\hline \multicolumn{5}{|c|}{ Inequalities by sex, RGSC and 'Spearhead' classification } \\
\hline $\begin{array}{l}\text { Professional men non-Sp - unskilled men } \\
\text { 'Spearhead' }\end{array}$ & 16.2 & $14.1 \%$ & 6.3 & $24.3 \%$ \\
\hline $\begin{array}{l}\text { Professional women non-Sp - unskilled } \\
\text { women 'Spearhead' }\end{array}$ & 15.7 & $9.7 \%$ & 6.4 & $15.9 \%$ \\
\hline $\begin{array}{l}\text { Professional women non-Sp - unskilled } \\
\text { men 'Spearhead' }\end{array}$ & 17.8 & $10.3 \%$ & 7.6 & $16.7 \%$ \\
\hline
\end{tabular}




\section{Figure $5 \quad$ Per cent of life expectancy at birth spent free of LLTID by RGSC and 'Spearhead' classification: men and women in English LAs, 2001-03}

\section{Per cent}

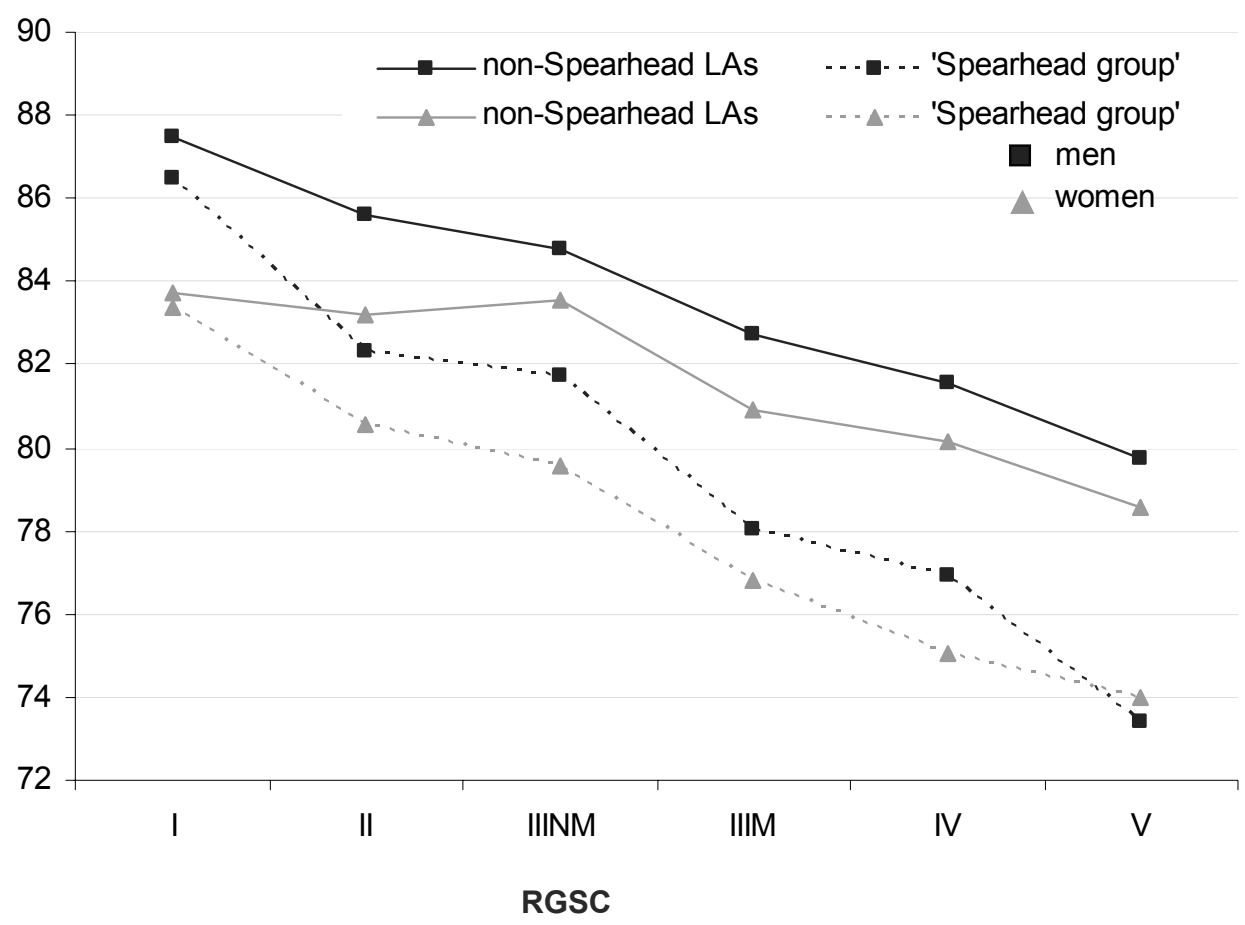

The results predominantly indicate that although men live shorter lives than women, they spend a higher proportion of their LE free of a LLTID within area type. However, this pattern is reversed in the case of the unskilled class in the 'Spearhead group'. The higher relative DFLE in men is particularly notable among professionals. Both sexes conform to a pattern of falling proportions of LE spent free of a LLTID with increasing socio-economic disadvantage, although the differences between social class II and social class IIINM are the smallest.

The scale of inequality in relative DFLE between professionals and the unskilled is almost twice as high in the 'Spearhead group' compared with the non-Spearhead LAs: a difference of 13.1 per cent between professional men and unskilled men, and a difference of 9.4 per cent between professional women and unskilled women. The larger relative difference observed in the 'Spearhead group' arises as a result of the much lower proportion of life spent free of a LLTID among unskilled men and women in these areas compared with their counterparts in the nonSpearhead LAs. Professionals are observed to have similar durations of life free of a LLTID in each area type.

The deterioration with increasing socio-economic disadvantage in the proportion of life expectancy at birth spent disability-free also applies at age 65 (Figure 6). 
Figure $6 \quad$ Per cent of life expectancy at age 65 spent free of LLTID by RGSC and 'Spearhead' classification: men and women in English LAs, 2001-03

\section{Per cent}

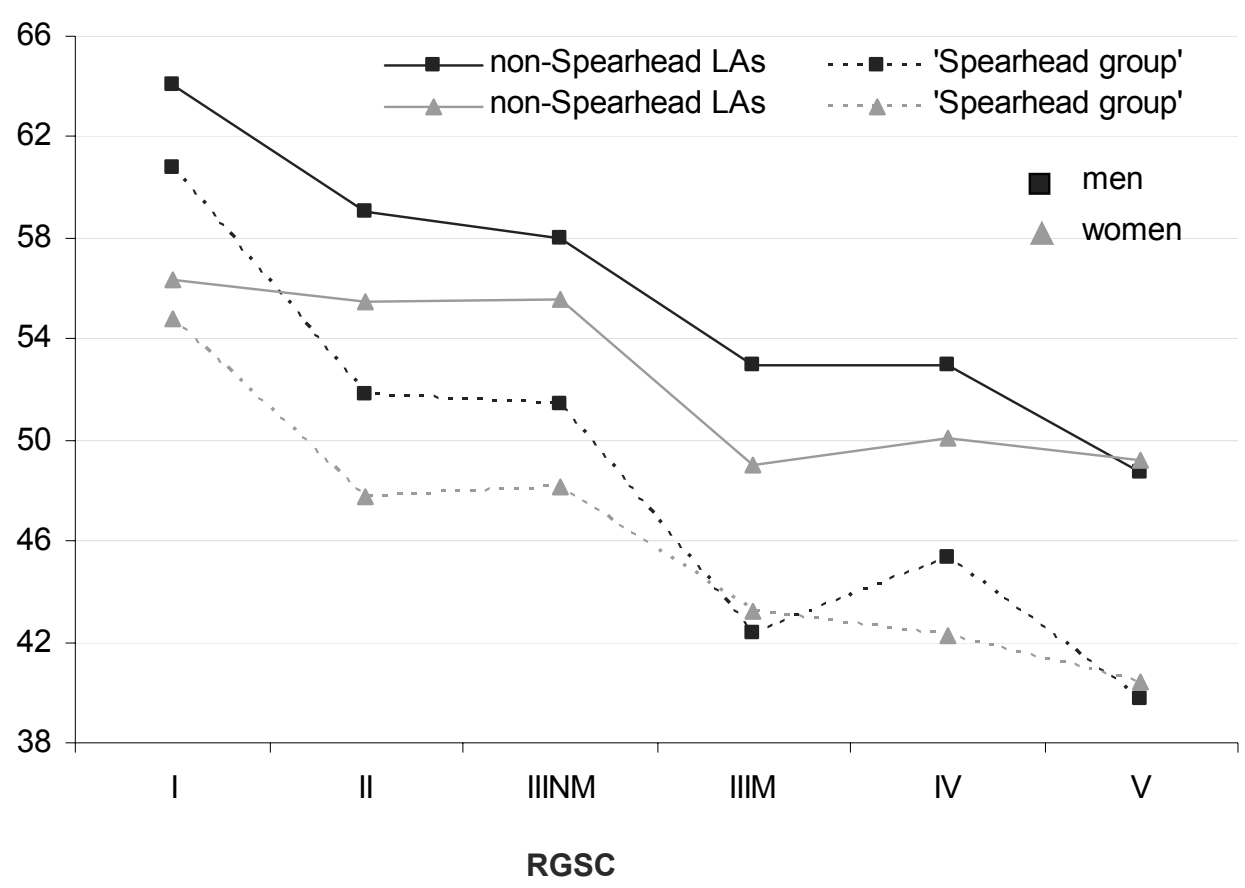

At age 65, unskilled women and skilled manual women in the 'Spearhead group' had higher proportions of their life expectancy free of a LLTID compared with men; this is reversed for all other social classes once adjusted for area type. Area type had a modest effect on the relative DFLE of professional men and women, but for all other classes, living in the 'Spearhead group' confers a notably lower proportion of LE spent free of a LLTID. Among men, the largest difference between the 'Spearhead group' and the non-Spearhead LAs occurred among the skilled manual class, who were disadvantaged in relative terms compared with their counterparts in non-Spearhead LAs.

The inequality between professionals and the unskilled in relative DFLE was higher at age 65 in both types of area than at birth; the difference in the gap was greater in the 'Spearhead group'. For men a difference of 21.0 per cent was found between professionals and the unskilled; for women the equivalent difference was 14.4 per cent.

\section{Discussion}

In this analysis DFLE based on functional health status, as recorded by the 2001 Census question on limiting long-term illness and disability has been compared across RGSC social classes and a grouping of local authorities based on the Department of Health's Spearhead classification.

\section{Differences in disability-free life expectancy by social class}

The differences observed in DFLE at birth and at age 65 between people assigned to the professional and unskilled social classes are statistically significant and substantial, demonstrating a clear social inequality in the amount of life, the functional capacity and performance during those 
years lived, the absolute number of years free of a LLTID, and thus the relative proportion of life spent free of limiting illness or disability.

At age 65 statistically significant differences between professionals and the unskilled persist, but are of a lower order of magnitude in absolute terms; however, in relative terms the differences are more substantial. This indicates that the effect of socio-economic position on DFLE endures after retirement.

The results estimated for DFLE are similar to those for HLE, and therefore the broad four-group classificatory pattern by socio-economic position for men and women at birth and at age 65 reported in the article on HLE also applies for DFLE. ${ }^{*}$

A higher DFLE at birth among women is predominantly present at the England level within social classes, although professional men and women have comparable DFLE. This differs from the sex comparison in HLE at birth where women had statistically significantly higher HLE in all social classes, including professionals. However, the generally higher DFLE of women reported in national estimates disguises the effect of socio-economic position, in that men assigned to the nonmanual social classes have higher DFLE than women assigned to the manual classes, emphasising the importance of socio-economic position on longevity free of limiting illness or disability.

The level of social disparity is more marked among men than among women in measures of DFLE at birth. This mainly arises from the relatively lower DFLE among unskilled men compared with women, while the DFLEs of professionals are comparable between the sexes. A larger gradient in men is also present at age 65. The importance of exposure to occupational hazards and their duration varying by sex is of greater significance in explaining differences in estimates of DFLE which attempt to measure functional health status; longer exposures to occupational hazards among the manual classes may represent a plausible mechanism for the steeper gradients observed.

\section{Disability-free life expectancy by social class and LA 'Spearhead' status}

The influence of area on class specific DFLE at birth was uniform for men and women. Professionals had comparable DFLEs, while for the other social classes DFLE is statistically significantly lower in the 'Spearhead group'. The resilience of the Professional class to unfavourable area circumstances is consistent with a threshold of social advantage effect found in previous analyses, which, once achieved, in terms of material affluence and social status, dominates or compensates for the hazards associated with the area of residence.

Living in the 'Spearhead group' has the effect of accentuating an already substantial inequality between professional men and women and unskilled men and women at the all England level. Men and women assigned to the unskilled social class living in the 'Spearhead group' are the most disadvantaged population sub-groups in terms of longevity and in the proportion of life expectancy spent with LLTID. This suggests the effect of socio-economic position is modified by the social and material fabric of the area of residence, particularly among men. These interactions between area,

\footnotetext{
* Readers are referred to the article on HLE in this edition of Health Statistics Quarterly for exposition of four group classificatory pattern.
} 
gender and socio-economic position need further exploration, particularly taking account of the influence of social mobility and perhaps the social composition of households.

DFLEs at birth were statistically significantly higher for women than men in the non-Spearhead LAs if they were assigned to the managerial and technical, skilled manual or unskilled social classes; however, in the 'Spearhead group' sex differences were present among the skilled non-manual, skilled manual and partly skilled social classes. Consequently, the predominant within class statistically significant higher DFLEs experienced by women at the England level are affected by area type. Specifically, the presence of sex differences in DFLE at birth are conditioned both by socio-economic position and area type.

The additive effect of sex, social class and area lead to substantial absolute differences in DFLE. A professional woman living in the non-Spearhead LAs can expect to live 18 years longer free of a limiting long-term illness or disability than a man assigned to the unskilled social class living in the 'Spearhead group'. This represents a profound inequality, and a clear difference in both the service needs posed by these sub-groups of the population, and their fitness for work at both working age and post the state pension age.

The sex divide in the proportion of life spent free from limiting illness or disability is largely inverted to the pattern in absolute differences. Men live shorter lives compared to women, but spend a higher proportion free of limiting illness or disability. Consequently, the greater longevity of women is accompanied by longer durations with a limiting long-term illness or disability, suggesting the health and social care needs of women will exceed that of men in each social class and area.

\section{Conclusion}

This analysis reports DFLE by socio-economic position and area type, and establishes clear differences in longevity free of limiting illness or disability between the social classes in a predominant linear pattern with DFLE increasing with increasing social advantage in each type of area investigated. However within class DFLE at birth for men and women is found to be lower in the 'Spearhead group', and statistically significantly lower among all classes other than professionals.

These results confirm that the assumptions made with regard to sex differences in DFLE need to be set in the context of socio-economic position, and assumptions made regarding sex and social differences need to set in the context of geography. 


\section{References}

1 Bebbington A and Bajekal M (2003) 'Sub-national variations in Health Expectancy', in Robine J et al (ed.) Determining Health Expectancies Wiley, 127-147.

2 Bajekal M (2005) 'Healthy Life Expectancy by area deprivation: magnitude and trends in England, 1994-1999' Health Statistics Quarterly 2519-27. Available on the Office for National Statistics website at: www.statistics.gov.uk/cci/article.asp?ID=1575\&Pos=1\&ColRank=1\&Rank=1

3 Rasulo D, Bajekal M and Yar M (2007) 'Inequalities in HEs in England and Wales - small area analysis from the 2001 Census' Health Statistics Quarterly 34 35-45. Available on the Office for National Statistics website at: www.statistics.gov.uk/cci/SearchRes2.asp?IPS $=10 \& C T=6 \& T e r m=\& A d v=Y \& J r n=22 \& \mathrm{Vol}=\& V \mathrm{VC}=\& \mid \mathrm{s}$ $\underline{s=34 \& M t h=0 \& Y r=2007 \& A u t=826}$

4 Pampalon R and Rochon M (2001) Health expectancy and deprivation in Quebec, 1996-98. Conference presentation, REVES 13, Vancouver.

5 Wilkins R, Mayer F, Ross N and Berthelot J M (2001) Health expectancy by neighbourhood income in Canada. Conference presentation REVES 13, Vancouver.

6 Office for National Statistics (2006) 'HEs for LAs in England and Wales, 2001' Health Statistics Quarterly 32 87-97. Available on the Office for National Statistics website at: www.statistics.gov.uk/downloads/theme health/HSQ32.pdf

7 Bebbington, A. (1993). Regional and social variations in disability-free life expectancy in Great Britain. In: Robine, JM, Mathers, C., Bone, M., and Romieu, I (eds) Calculation of Health Expectancy: Harmonisation, Consensus achieved and future perspectives, Mountrouge, John Libbey Eurotext.

8 Hattersley L (1999) 'Trends in life expectancy by social class - an update' Health Statistics Quarterly 02, 16-24. Available on the Office for National Statistics website at: www.statistics.gov.uk/cci/article.asp?|ID=1210\&Pos=1\&ColRank=1\&Rank=374

9 Donkin A, Goldblatt P and Lynch K (2002) 'Inequalities in life Expectancy by social class, 19721999' Health Statistics Quarterly 15, 5-15. Available on the Office for National Statistics website at: www.statistics.gov.uk/cci/article.asp?ID=1523\&Pos=1\&ColRank=1\&Rank=1

10 Office for National Statistics (2007) Trends in Life Expectancy by social class. Available on the Office for National Statistics website at: www.statistics.gov.uk/StatBase/Product.asp? vlnk=8460\&Pos=3\&ColRank=1\&Rank=272

11 Melzer D et al (2000) 'Socio-economic status and the expectation of disability in old age: estimates for England' JECH: 54, 286-292.

12 Department of Health (2004) Tackling health inequalities: the spearhead group of LAs and Primary Care Trusts. London. 
13 Hattersley L and Creeser R (1995) The Longitudinal Study, 1971-1991: History, Organisation and Quality of data. LS Series No.7 HMSO. London.

14 Blackwell L, Lynch K, Smith J and Goldblatt P (2003) Longitudinal Study 1971-2001:

Completeness of Census Linkage LS Series No. 10 London.

www.celsius.Ishtm.ac.uk/documents/LS10.pdf

15 Jagger C (1999) Health expectancy calculation by the Sullivan method: A practical guide NUPRI Research Paper Series No 68, Toyko 


\section{Annex}

Table A1 Life Expectancy and DFLE at birth and at age 65 by RGSC: England, 2001-03

\begin{tabular}{|c|c|c|c|c|c|c|}
\hline \multirow[b]{2}{*}{ At Birth } & \multirow[t]{2}{*}{ Social Class } & \multicolumn{2}{|l|}{ Life expectancy } & \multicolumn{2}{|c|}{ Disability-free life expectancy } & \multirow[b]{2}{*}{$\begin{array}{r}\text { HLE as a } \\
\text { proportion of } \\
\text { LE (\%) }\end{array}$} \\
\hline & & Years & Years & $\begin{array}{r}\text { Lower } 95 \% \\
\text { confidence } \\
\text { interval }\end{array}$ & $\begin{array}{r}\text { Upper } 95 \% \\
\text { confidence } \\
\text { interval }\end{array}$ & \\
\hline \multirow[t]{6}{*}{ Men } & 1 & 80.2 & 70.2 & 69.4 & 71.0 & 87.5 \\
\hline & II & 78.9 & 67.1 & 66.7 & 67.5 & 85.0 \\
\hline & IIINM & 78.4 & 65.9 & 65.4 & 66.5 & 84.1 \\
\hline & IIIM & 76.4 & 62.1 & 61.8 & 62.4 & 81.3 \\
\hline & IV & 75.9 & 60.8 & 60.3 & 61.3 & 80.0 \\
\hline & V & 73.5 & 56.8 & 55.5 & 58.1 & 77.3 \\
\hline England & & 77.1 & 63.6 & 63.4 & 63.8 & 82.4 \\
\hline UK 2001-03* & & 75.9 & 60.9 & 60.6 & 61.2 & 80.2 \\
\hline \multirow[t]{6}{*}{ Women } & 1 & 85.5 & 71.6 & 70.7 & 72.5 & 83.8 \\
\hline & II & 82.8 & 68.4 & 67.8 & 69.1 & 82.7 \\
\hline & IIINM & 82.2 & 67.9 & 67.4 & 68.4 & 82.6 \\
\hline & IIIM & 80.6 & 64.2 & 63.8 & 64.5 & 79.6 \\
\hline & IV & 79.9 & 62.7 & 62.0 & 63.5 & 78.5 \\
\hline & V & 78.7 & 60.4 & 59.6 & 61.3 & 76.8 \\
\hline England & & 81.3 & 65.8 & 65.6 & 66.1 & 80.9 \\
\hline UK 2001-03* & & 80.5 & 63.0 & 62.7 & 63.3 & 78.3 \\
\hline \multicolumn{7}{|l|}{ At age 65} \\
\hline \multirow[t]{6}{*}{ Men } & I & 18.3 & 11.6 & 11.1 & 12.1 & 63.6 \\
\hline & II & 17.9 & 10.4 & 10.1 & 10.6 & 57.8 \\
\hline & IIINM & 17.4 & 9.9 & 9.5 & 10.2 & 56.6 \\
\hline & IIIM & 16.0 & 7.9 & 7.8 & 8.1 & 49.7 \\
\hline & IV & 15.7 & 7.9 & 7.7 & 8.2 & 50.7 \\
\hline & V & 13.9 & 6.3 & 5.9 & 6.7 & 45.3 \\
\hline England & & 16.5 & 8.8 & 8.7 & 8.9 & 53.4 \\
\hline UK 2001-03* & & 16.1 & 9.0 & 8.8 & 9.3 & 55.9 \\
\hline Women & 1 & 22.7 & 12.8 & 12.2 & 13.4 & 56.4 \\
\hline
\end{tabular}




\begin{tabular}{lrrrrrr}
\hline II & 21.3 & 11.5 & 11.2 & 11.7 & 54.1 \\
IIINM & 20.2 & 10.9 & 10.7 & 11.1 & 53.9 \\
IIIM & 18.7 & 8.8 & 8.6 & 9.1 & 47.2 \\
IV & 19.1 & 9.1 & 8.9 & 9.3 & 47.7 \\
England & $\mathrm{V}$ & 17.6 & 8.1 & 7.8 & 8.5 & 46.2 \\
UK 2001-03* & & 19.7 & 10.1 & 9.9 & 10.2 & 50.9 \\
\hline
\end{tabular}

Notes: UK 2001-03* Based on ONS standard health expectancies calculations published in HSQ 29, 59-62

www.statistics.gov.uk/downloads/theme health/HSQ29.pdf 
Table A2 Life Expectancy and DFLE at birth and at age 65, by RGSC in the 'Spearhead group' and non-Spearhead LAs: men and women in English LAs, 2001-03

\begin{tabular}{|c|c|c|c|c|c|c|c|c|c|c|}
\hline \multirow{3}{*}{ At Birth } & \multicolumn{2}{|c|}{ Life Expectancy } & \multicolumn{8}{|c|}{ Healthy life expectancy } \\
\hline & \multirow[b]{2}{*}{ non-Sp } & \multicolumn{2}{|l|}{ Years } & Years & \multicolumn{2}{|c|}{$\begin{array}{r}\text { Lower } 95 \% \\
\text { confidence } \\
\text { interval }\end{array}$} & \multicolumn{2}{|c|}{$\begin{array}{r}\text { Upper } 95 \% \\
\text { confidence } \\
\text { interval }\end{array}$} & \multirow{2}{*}{$\begin{array}{r}\text { HLE as per } \\
\text { cent of LE } \\
\text { non-Sp }\end{array}$} & \multirow{2}{*}{$\begin{array}{l}\text { HLE as per } \\
\text { cent of LE }\end{array}$} \\
\hline & & SG & non-Sp & $S G$ & non-Sp & SG & n-Sp & SG & & \\
\hline \multicolumn{11}{|l|}{ Men } \\
\hline I & 80.3 & 79.5 & 70.3 & 68.8 & 69.3 & 66.8 & 71.2 & 70.8 & 87.5 & 86.5 \\
\hline II & 79.1 & 78.2 & 67.7 & 64.4 & 67.3 & 63.4 & 68.2 & 65.3 & 85.6 & 82.3 \\
\hline IIINM & 79.2 & 75.7 & 67.1 & 61.9 & 66.5 & 60.7 & 67.8 & 63.0 & 84.8 & 81.7 \\
\hline IIIM & 76.7 & 75.6 & 63.5 & 59.0 & 63.1 & 58.5 & 63.9 & 59.6 & 82.8 & 78.0 \\
\hline IV & 76.2 & 75.4 & 62.1 & 58.0 & 61.5 & 57.2 & 62.7 & 58.8 & 81.5 & 76.9 \\
\hline V & 73.5 & 73.6 & 58.6 & 54.0 & 57.5 & 51.8 & 59.7 & 56.2 & 79.7 & 73.4 \\
\hline All classes & 77.6 & 75.9 & 65.0 & 59.8 & 64.7 & 59.4 & 65.2 & 60.1 & 83.7 & 78.8 \\
\hline England & \multicolumn{2}{|l|}{77.1} & \multicolumn{2}{|l|}{63.5} & \multicolumn{2}{|c|}{63.4} & \multicolumn{2}{|c|}{63.7} & \multicolumn{2}{|c|}{82.4} \\
\hline UK 2001-03* & \multicolumn{2}{|c|}{75.9} & \multicolumn{2}{|l|}{60.9} & \multicolumn{2}{|c|}{60.6} & \multicolumn{2}{|c|}{61.2} & \multicolumn{2}{|c|}{80.2} \\
\hline \multicolumn{11}{|l|}{ Women } \\
\hline I & 85.8 & 83.5 & 71.9 & 69.6 & 70.6 & 66.9 & 73.2 & 72.2 & 83.7 & 83.4 \\
\hline II & 83.4 & 80.4 & 69.4 & 64.7 & 68.8 & 63.1 & 70.0 & 66.4 & 83.2 & 80.5 \\
\hline IIINM & 82.4 & 81.7 & 68.8 & 65.0 & 67.7 & 63.9 & 69.9 & 66.0 & 83.5 & 79.5 \\
\hline IIIM & 81.2 & 79.3 & 65.7 & 60.9 & 65.2 & 60.3 & 66.1 & 61.5 & 80.9 & 76.8 \\
\hline IV & 79.6 & 80.4 & 63.8 & 60.3 & 62.6 & 59.5 & 65.0 & 61.1 & 80.2 & 75.0 \\
\hline V & 80.5 & 75.9 & 63.2 & 56.2 & 62.1 & 54.8 & 64.4 & 57.6 & 78.6 & 74.0 \\
\hline All classes & 81.9 & 79.8 & 67.3 & 62.0 & 67.0 & 61.5 & 67.6 & 62.5 & 82.1 & 77.7 \\
\hline England & \multicolumn{2}{|l|}{81.3} & \multicolumn{2}{|l|}{65.8} & \multicolumn{2}{|c|}{65.6} & \multicolumn{2}{|c|}{66.1} & \multicolumn{2}{|c|}{80.9} \\
\hline UK 2001-03* & \multicolumn{2}{|l|}{80.5} & 63.0 & & 62.7 & & 63. & & 78. & \\
\hline At age 65 & & & & & & & & & & \\
\hline Men & & & & & & & & & & \\
\hline I & 18.4 & 17.3 & 11.8 & 10.5 & 11.3 & 9.5 & 12.3 & 11.6 & 64.1 & 60.8 \\
\hline II & 17.9 & 18.1 & 10.6 & 9.4 & 10.3 & 8.8 & 10.8 & 10.0 & 59.0 & 51.8 \\
\hline IIINM & 17.7 & 16.2 & 10.3 & 8.3 & 9.9 & 7.7 & 10.7 & 9.0 & 58.0 & 51.4 \\
\hline IIIM & 16.2 & 15.5 & 8.6 & 6.5 & 8.4 & 6.3 & 8.8 & 6.8 & 53.0 & 42.4 \\
\hline IV & 15.8 & 15.6 & 8.4 & 7.1 & 8.0 & 6.6 & 8.7 & 7.5 & 53.0 & 45.3 \\
\hline V & 14.0 & 13.9 & 6.8 & 5.5 & 6.3 & 4.9 & 7.4 & 6.1 & 48.7 & 39.7 \\
\hline
\end{tabular}




\begin{tabular}{|c|c|c|c|c|c|c|c|c|c|c|}
\hline All classes & 16.8 & 15.9 & 9.4 & 7.3 & 9.3 & 7.1 & 9.6 & 7.5 & 56.1 & 45.9 \\
\hline England & 16.5 & & 8.8 & & 8.7 & & 8.9 & & 53.4 & \\
\hline UK 2001-03* & 16.1 & & 9.1 & & 8.8 & & 9.3 & & 56.5 & \\
\hline \multicolumn{11}{|l|}{ Women } \\
\hline I & 23.2 & 20.3 & 13.1 & 11.1 & 12.4 & 9.2 & 13.7 & 13.0 & 56.4 & 54.8 \\
\hline II & 21.4 & 20.9 & 11.9 & 10.0 & 11.6 & 9.4 & 12.1 & 10.5 & 55.4 & 47.8 \\
\hline IIINM & 20.4 & 19.8 & 11.3 & 9.5 & 11.1 & 9.1 & 11.6 & 10.0 & 55.6 & 48.1 \\
\hline IIIM & 19.0 & 18.1 & 9.3 & 7.8 & 9.1 & 7.5 & 9.6 & 8.2 & 49.0 & 43.2 \\
\hline IV & 19.2 & 19.0 & 9.6 & 8.0 & 9.4 & 7.6 & 9.9 & 8.4 & 50.1 & 42.2 \\
\hline V & 18.5 & 16.5 & 9.1 & 6.7 & 8.6 & 6.1 & 9.6 & 7.2 & 49.2 & 40.4 \\
\hline All classes & 20.1 & 18.8 & 10.6 & 8.5 & 10.5 & 8.3 & 10.8 & 8.7 & 53.0 & 45.0 \\
\hline England & 19.7 & & 10.1 & & 9.9 & & 10.2 & & 50.9 & \\
\hline UK 2001-03* & 19.1 & & 10.3 & & 10.1 & & 10.5 & & 53.9 & \\
\hline
\end{tabular}

non-Sp = non-Spearhead LAs; SG = 'Spearhead group'

UK 2001-03* Based on ONS standard Health Expectancies calculations published in HSQ 29, 59-62

www.statistics.gov.uk/downloads/theme health/HSQ29.pdf 